\title{
Creatine kinase $B$ deficient neurons exhibit an increased fraction of motile mitochondria
}

\author{
Jan WP Kuiper, Frank TJJ Oerlemans, Jack AM Fransen and Bé Wieringa*
}

Address: Department of Cell Biology, Radboud University Nijmegen Medical Centre, P.O. Box 9101, 6500 HB Nijmegen, The Netherlands Email: Jan WP Kuiper - j.kuiper@ncmls.ru.nl; Frank TJJ Oerlemans - f.oerlemans@ncmls.ru.nl; Jack AM Fransen - j.fransen@ncmls.ru.nl; Bé Wieringa* - b.wieringa@ncmls.ru.nl

* Corresponding author

Published: 28 July 2008

BMC Neuroscience 2008, 9:73 doi:10.1 |86/|47|-2202-9-73

This article is available from: http://www.biomedcentral.com/I47I-2202/9/73

(C) 2008 Kuiper et al; licensee BioMed Central Ltd.

This is an Open Access article distributed under the terms of the Creative Commons Attribution License (http://creativecommons.org/licenses/by/2.0), which permits unrestricted use, distribution, and reproduction in any medium, provided the original work is properly cited.
Received: 22 January 2008

Accepted: 28 July 2008

\begin{abstract}
Background: Neurons require an elaborate system of intracellular transport to distribute cargo throughout axonal and dendritic projections. Active anterograde and retrograde transport of mitochondria serves in local energy distribution, but at the same time also requires input of ATP. Here we studied whether brain-type creatine kinase (CK-B), a key enzyme for high-energy phosphoryl transfer between ATP and CrP in brain, has an intermediary role in the reciprocal coordination between mitochondrial motility and energy distribution. Therefore, we analysed the impact of brain-type creatine kinase (CK-B) deficiency on transport activity and velocity of mitochondria in primary murine neurons and made a comparison to the fate of amyloid precursor protein (APP) cargo in these cells, using live cell imaging.

Results: Comparison of average and maximum transport velocities and global transport activity showed that CK-B deficiency had no effect on speed of movement of mitochondria or APP cargo, but that the fraction of motile mitochondria was significantly increased by $36 \%$ in neurons derived from CK-B knockout mice. The percentage of motile APP vesicles was not altered.

Conclusion: CK-B activity does not directly couple to motor protein activity but cells without the enzyme increase the number of motile mitochondria, possibly as an adaptational strategy aimed to enhance mitochondrial distribution versatility in order to compensate for loss of efficiency in the cellular network for ATP distribution.
\end{abstract}

\section{Background}

Neurons, by virtue of their unique architecture, have developed specific transport systems to regulate anterograde and retrograde flow of macromolecules, vesicles or organelles between the cell body and distal regions in the axon and dendrites. To maintain efficiency and directionality in the bidirectional flow of these cellular constituents strict control over movement of cargo by motor proteins on cytoskeletal elements such as microtubules, intermediate filaments, and actin, is needed [1-3]. One of the basic elements in this control is adequate fuelling with ATP, the major carrier of cellular energy. Homeostasis of global and compartmentalized ATP levels, i.e. regulation of production, distribution, and consumption of intracellular ATP, is controlled by an elaborate metabolic network, which varies with cell type. In neurons this circuit involves both cytosolic-glycolytic and oxidative mitochondrial production pathways and a high level of ATP consumption for fuelling of acto-myosin dynamics, ion transporters, and neurotransmitter cycling activity in the synapse 
[4-6]. Neurons use glucose from the circulation as the main carbohydrate source for ATP production, but depending on specific physiological conditions - a fair percentage of their energy may also be derived from lactate, which they exchange with astrocytes $[7,8]$, or from ketone bodies imported from circulation. Because of the highly branched morphology of neurons, sites of energy consumption are usually spatially separated from sites of energy generation in this cell type. Since diffusion of ATP might usually be too slow to achieve optimal supply of high-energy phosphoryl groups $(\sim \mathrm{P})$, neurons have developed more efficient mechanisms for transport and distribution of $\sim \mathrm{P}$. One way to minimize the diffusion distance of ATP and regulating natural inhomogeneity in ATPs intracellular distribution is by redirecting mitochondria to sites were ATP demand is high, e.g. in the vicinity of synapses [9]. This requires active mitochondrial transport, which is mainly driven by members of the kinesin and dynein superfamilies of microtubule directed motor proteins such as KIF1B $\alpha$ and KIF5 [10,11], although, actin guided motility may also be involved [12-14].

An alternative strategy to optimize spatial energy transfer within cells is to relay high-energy phosphoryl groups $(\sim \mathrm{P})$ by enzymatic transfer systems, such as the creatine kinase (CK) family of isozymes [15]. These enzymes buffer ATP and ADP levels by the reversible transfer of $\sim P$ onto creatine $(\mathrm{Cr})\left(\mathrm{MgATP}^{2-}+\mathrm{Cr} \leftrightarrow \mathrm{MgADP}^{-}+\mathrm{CrP}^{2-}+\mathrm{H}^{+}\right)$ $[15,16]$. Indeed, CKs are mainly expressed in tissues with high energy-turnover and sudden rises in energy demand, such as muscle and brain $[17,18]$. Ubiquitous mitochondrial CK (UbCKmit) and cytosolic brain-type CK (CK-B) are the two predominant isoforms in brain $[17,19]$ and broadly distributed throughout neurons (moderate-low expression) and glial cells (high expression in astrocytes and microglia) across different brain areas. The CK system provides cells with both a temporal and spatial energy buffer $[15,16]$. During transient rises in energy consumption, the CrP pool is addressed by CK to provide the cell with ATP $[18,20]$. In addition, CK isozymes connect spatially separated subcellular locales of ATP generation and ATP hydrolysis [21,22]

We have demonstrated that genetic ablation of CK-B in mice causes changes in behavior, diminished performance in spatial learning tasks and delayed development of pentylenetetrazole-induced seizures [17]. Furthermore, the intra- and infrapyramidal mossy fiber areas in CK-B-/mice appeared increased. We explained these features by diminished synaptic plasticity or compensatory adaptation with altered neuronal outgrowth during development.
Here we investigated whether compromised intracellular energy transport could underlie the diminished synaptic plasticity or altered morphology (in analogy to [23-25]).

Intracellular transport in neurons is comprised of membranous organelles and cytoplasmic proteins (or protein complexes) that are conveyed from the cell body to the synapse, and vice versa, by either fast or slow axonal transport [1]. In general, movement of organelles is mediated by fast axonal transport, whereas cytosolic and cytoskeletal proteins move at a slower pace. This difference in velocity is attributed to the duty ratio of the motor proteins involved in both types of transport $[1,26]$.

CK-B was identified in slow component B (SCb) which, together with slow component $\mathrm{A}$ ( $\mathrm{SCa}$ ), make up the branch of slow axonal transport [27]. However, it is not known if CK-B facilitates this particular type of axonal transport, or that it is merely transported as inert cargo to subcellular destinations where it is needed. To address the question whether CK-B enzymatically contributes to axonal transport in more detail, we compared cultured primary hippocampal neurons derived from CK-B knockout and wildtype mice and monitored the fate of YFP tagged amyloid precursor protein (APP) as a representative component in fast transport. This type of transport correlates with a high duty ratio of motor proteins and with high ATPase activity. In addition, we analysed mitochondrial dynamics. Our results suggest that CK-B does not influence the velocity of intracellular transport of APP or mitochondria in neurons. Rather, cells deficient in CK$B$ display show a conspicuous alteration in magnitude of transport, concomitant with an increase in the fraction of motile mitochondria.

\section{Results}

\section{Distribution of CK-B in primary neurons}

To assess effects of CK-B efficiency in primary neurons, we used a co-culture system of hippocampus-derived neurons on a monolayer of primary astrocytes (see material and methods). Neuronal expression of CK-B has been demonstrated in several organisms, but not much is known about its subcellular localization $[28,29]$.

Immunolocalization on murine hippocampal neurons of different age with an isoform-specific antibody [30] showed that CK-B was evenly distributed throughout the entire cell body, and rarely detected in the nucleus. Figure 1 displays confocal images of hippocampal neurons, which were cultured for 1, 3 or 6 days in vitro (Figure 1a,b and $1 \mathrm{c}$, respectively). No obvious changes were observed in either the intensity or localization of CK-B during the 6day culture period. 

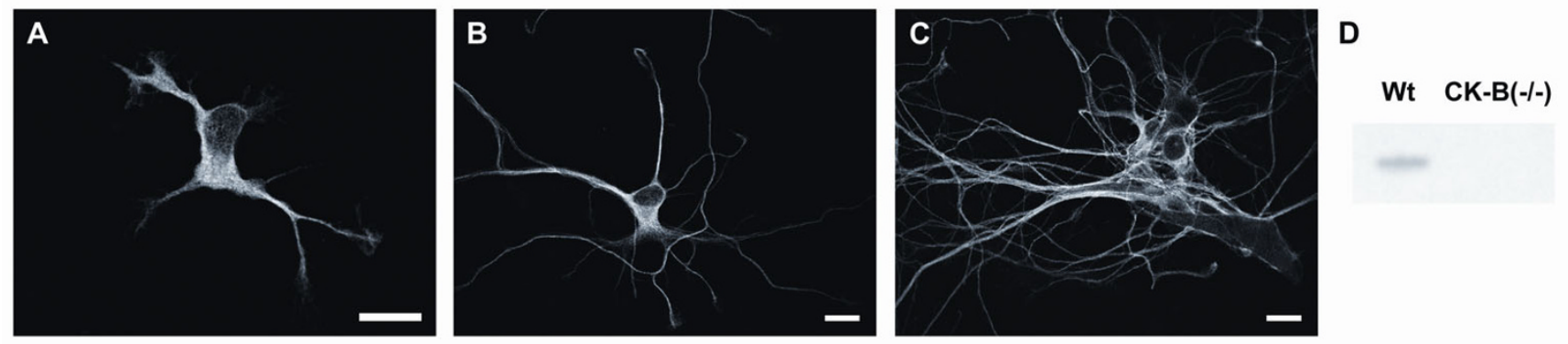

\section{Figure I}

Primary neurons derived from wildtype mice were co-cultured with astrocytes for I, 3 and 6 days. Subsequently, the cells were fixed and immunostained with an isoform specific monoclonal antibody against CK-B (2IEI0). Confocal images display the subcellular distribution of CK-B after A) I day, B) 3 days and C) 6 days. Image bars represent I0 $\mu$ m. D) Lysates were prepared from wildtype and CK-B deficient neurons ( $7 \mathrm{div}$ ) and zymogram analysis was applied to determine enzymatic CK activity.

Neurons derived from CK-B knockout mice did not display any positive immunostaining with our antibody, demonstrating specificity of our assay (data not shown). In addition to localization studies, we also performed zymogram analysis on cultured primary neurons to assess enzymatic activity. As expected, CK-B catalytic activity was present in wildtype cells, but was completely absent in CK-B knockout cells (Figure 1d).

\section{APP-transport in CK-B deficient neurons}

To investigate a possible role for CK-B in axonal transport, we focused on the amyloid precursor protein (APP). APP is a membrane spanning type-1 protein which is conveyed from the cell body to the synapse by fast axonal transport [31-33]. The kinesin KIF-I was identified as the tubulin directed motor protein responsible for APP transport [33] and real time live imaging revealed that APP fused to Yellow Fluorescent Protein (YFP) is transported over long distances with speeds up to $9 \mu \mathrm{m} / \mathrm{s}$ [32]. To maintain this dynamics a continuously high supply of ATP is needed for motor protein functioning. To test whether CK-B mediated $\sim \mathrm{P}$ transfer has a role in safeguarding this process, we compared the appearance and movements of APP containing vesicles in wildtype and CK-B knockout neurons after transfection with YFP-tagged APP. In Figure 2a we show 5 successive frames of a time-lapse registration of a cell with APP-YFP. Careful analysis demonstrated that APP was transported in elongated tubular vesicles, confirming earlier observations by Kaether et al. [32]. Vesicle appearance did not overtly differ between wildtype and CK-B knockout cells. For further comparison, 45 and 53 APP-YFP containing vesicles from wildtype and knockout cells, respectively, were tracked and their average velocities calculated. Figure $2 \mathrm{~b}$ shows that the distribution of velocities was similar for both types of cells. On average, APP-YFP vesicles moved at $1.12 \pm 0.49$ and $1.07 \pm 0.47$ $\mu \mathrm{m} / \mathrm{s}$ for wildtype and CK-B knockout, respectively.
Because vesicles sometimes changed their speed during time-lapse recording, we also calculated the maximum velocity for each vesicle during one recording. In figure $2 \mathrm{c}$ these maximum values are displayed. Maximal velocities found were comparable, with $1.60 \pm 0.62 \mu \mathrm{m} / \mathrm{s}$ for APPYFP vesicles in wildtype cells and $1.54 \pm 0.55 \mu \mathrm{m} / \mathrm{s}$ for CK$\mathrm{B}$ knockout cells. Also no difference was found in the distribution of maximal velocities. Both knockout and wildtype vesicles reach maximal velocities up to $3 \mu \mathrm{m} / \mathrm{s}$. It may be of note here, that this is 3 times slower than the maximum and 4 times slower than the average velocities of APP reported in rat primary neurons [32].

\section{Mitochondrial transport in CK-B deficient neurons}

Mitochondrial transport and repositioning is an important mechanism for neurons to comply with alterations in local energy demand. Fission, fusion and intracellular motility are essential processes involved in the regulation of subcellular distribution of mitochondria. It is therefore not surprising that many neurodegenerative diseases are associated with perturbations of these processes $[2,34]$. To investigate if CK-B coordinates the fueling role and transport fate of mitochondria, we compared the dynamic behavior of mitochondria between primary hippocampal neurons from wildtype and CK-B knockout mice. Staining with rhodamine 123 to visualize mitochondria and timelapse recording and subsequent image analysis were used to determine the average mitochondrial velocity (Figure 3a). Mitochondria included in the analysis traveled a minimum of 3 frames and were tracked till they stopped or reversed direction. Mitochondria from wildtype cells traveled at an average velocity of $0.59 \pm 0.26 \mu \mathrm{m} / \mathrm{s}$, which was almost identical to CK-B knockout cells $(0.57 \pm 0.24$ $\mu \mathrm{m} / \mathrm{s})$. Furthermore, frequency histogram analysis revealed no differences in the distribution of average mitochondrial velocity (Figure 3b), suggesting that there is also no subset of mitochondrial movements that is 
A
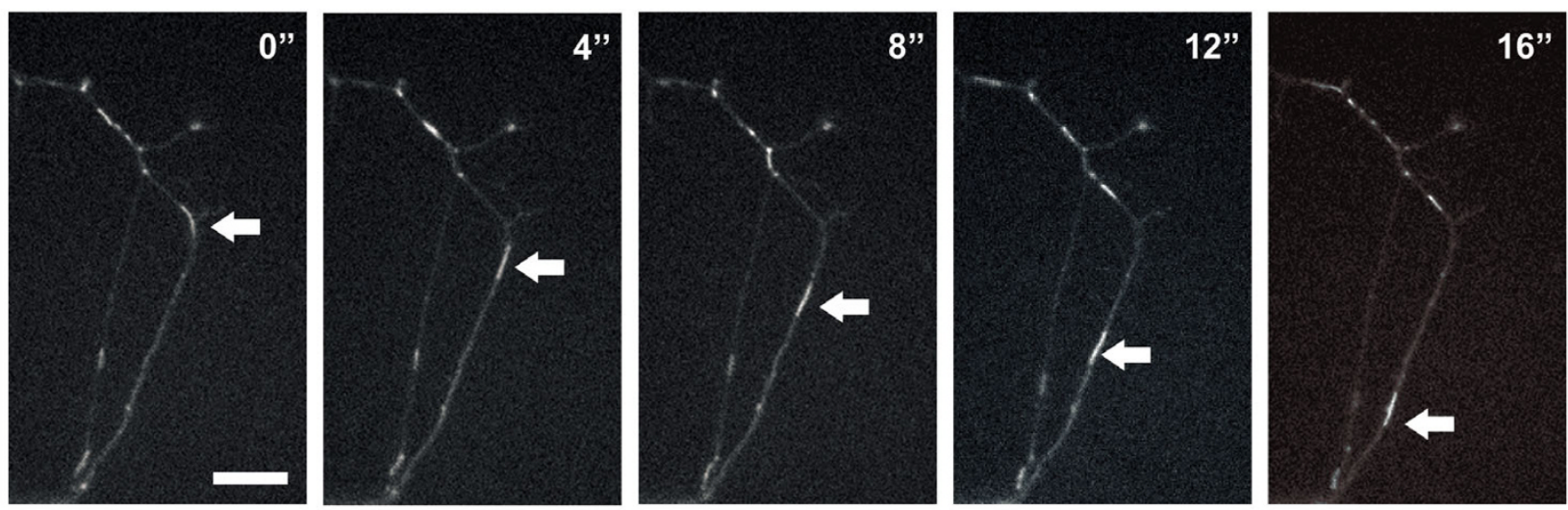

B

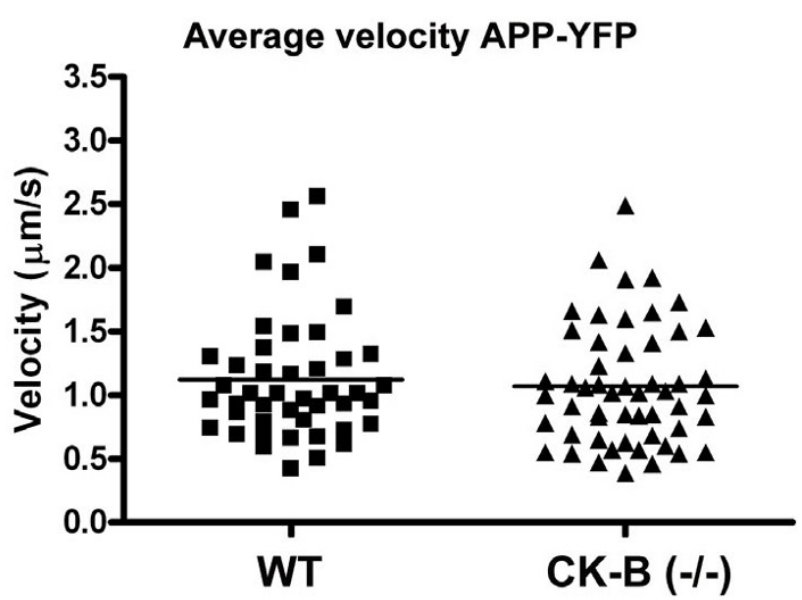

C

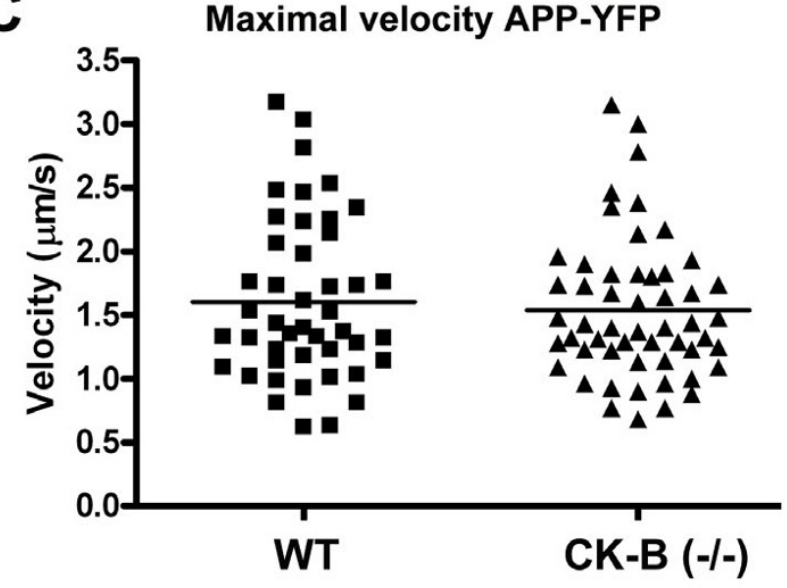

Figure 2

7-day-old CK-B deficient and wildtype neurons were transfected with plasmid DNA encoding APP-YFP. After 24 hours cells were subjected to live imaging at $37^{\circ} \mathrm{C}$ and $5 \% \mathrm{CO}_{2}$. Panel $\mathbf{A}$ shows 5 successive captures of a transfected neuron. An APPYFP-containing vesicle, which traverses the neuron, is marked by arrows. The bar represents $10 \mu \mathrm{m}$. B) The average velocity of APP-YFP positive vesicles in both wildtype and CK-B deficient neurons was calculated and plotted in the diagram. For wildtype and CK-B (-/-) cells 45 vesicles and 53 vesicles were tracked, respectively. C) Maximum velocities for individual particles of wildtype and CK-B knockout cells were also plotted.

affected by CK-B deficiency. Because a single mitochondrion could vary its speed during the cause of one movement, we also calculated the maximum speed for every mitochondrion during its recording period. The bar-diagram in figure $3 c$ displays the average of maximal reached speeds of all tracked mitochondria in wildtype (1.13 \pm $0.43 \mu \mathrm{m} / \mathrm{s})$ and CK-B deficient cells $(1.07 \pm 0.38 \mu \mathrm{m} / \mathrm{s})$. A frequency distribution diagram of maximal speeds also revealed no significant differences in maximal velocities of mitochondria between knockout and wildtype cells (figure 3d).

Since CK-B deficiency had no impact on the average and maximal velocities by which mitochondria travel in neurites, we wondered if lack of CK-B mediated $\sim P$ transfer could elicit more subtle effects and have impact on the rate of engagement in intracellular transport or affect the process of anchorage of mitochondria, two types of events which are also believed to be regulated by local energy demand [35,36]. To answer this question, we analysed whether the fraction of mitochondria that was rendered motile might be affected by CK-B deficiency (Figure 4). Image stack difference analysis was applied to estimate the percentage of mitochondria that moved during the time of one recording ( 3 minutes). For wildtype cells $10.5 \pm$ $3.2 \%$ of mitochondria were motile at any moment during the course of one recording. Surprisingly, CK-B deficient cells showed a significant increase of 35\% $(\mathrm{p}<0.05)$ in motile mitochondria $(14.1 \pm 3.8 \%)$. The dot plot in figure $4 \mathrm{c}$ also clearly shows the shift towards more motile mitochondria in CK-B deficient cells. To validate this conclusion, we also applied a method with manual counting 
A
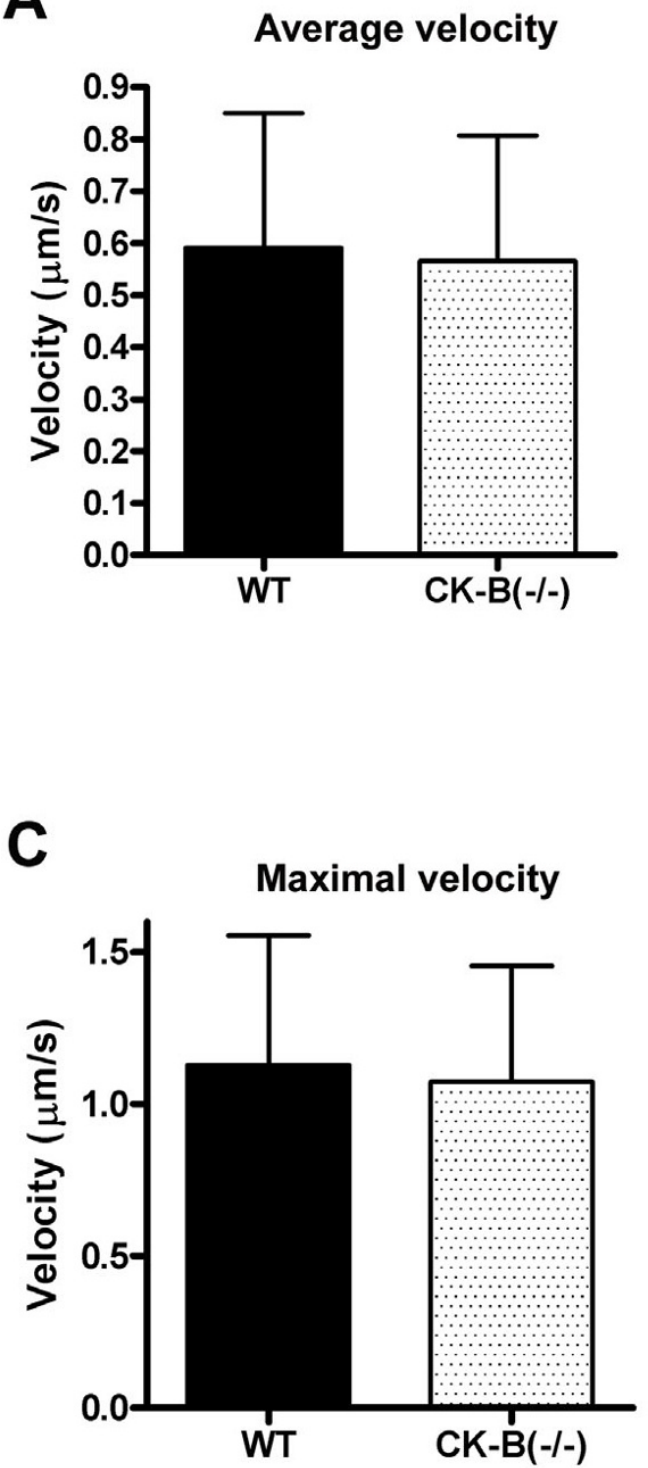

B

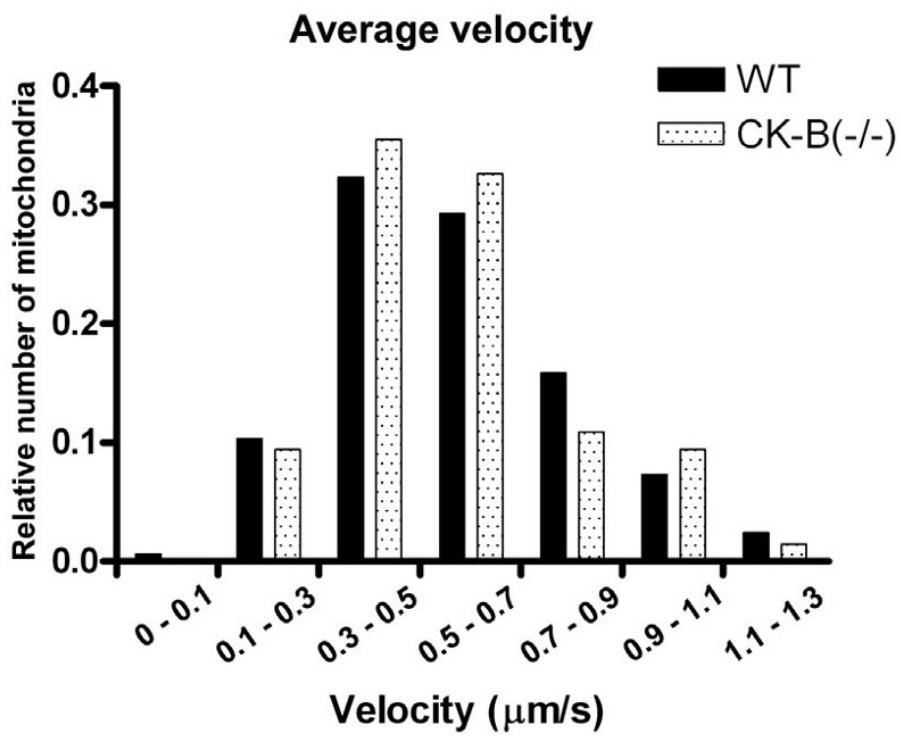

D

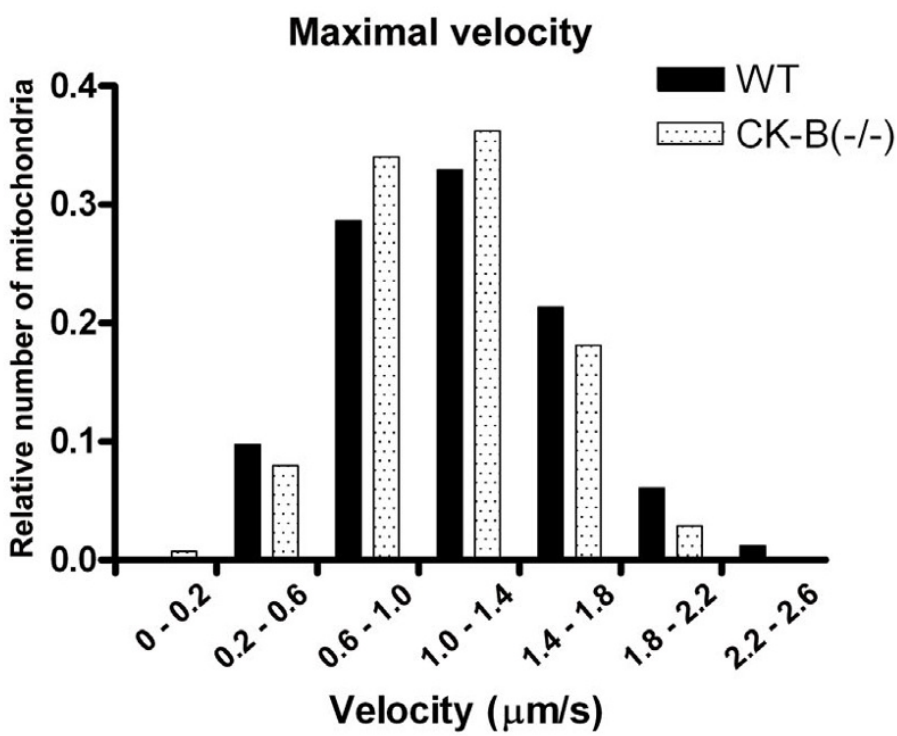

Figure 3

Mitochondria of 7-day-old CK-B deficient and wildtype neurons were stained with rhodamine I23. Live imaging was applied to track these mitochondria. Average velocities were determined for mitochondria of wildtype cells (I64 mitochondria) and CK$B$ deficient cells ( 138 mitochondria). The bar diagrams in panel $\mathbf{A}$, display average velocities with error bars representing the standard deviation (SD). Panel B shows the distribution of mitochondrial velocities. Maximum velocities for individual tracked mitochondria were also determined and the average of these are presented in panel C. Error bars represent SD. D) The distribution of maximal velocities of individual mitochondria are shown for wildtype and CK-B knockout neurons.

(see Additional file 1). Importantly, the outcome of this analysis was almost identical (37\% increase in the fraction of motile mitochondria in CK-B deficient neurons), although absolute percentages of motile mitochondria were lower with this method $(5.9 \% \pm 2.2 \%$ for wildtype and $8.1 \pm 2.0 \%$ for CK-B(-/-); $\mathrm{p}<0.0005$ ) (see figure in Additional file 2). When this same image analysis methodology was applied to YFP-APP vesicles, no significant effect of absence or presence of CK-B was found (Figure $4 d)$. 

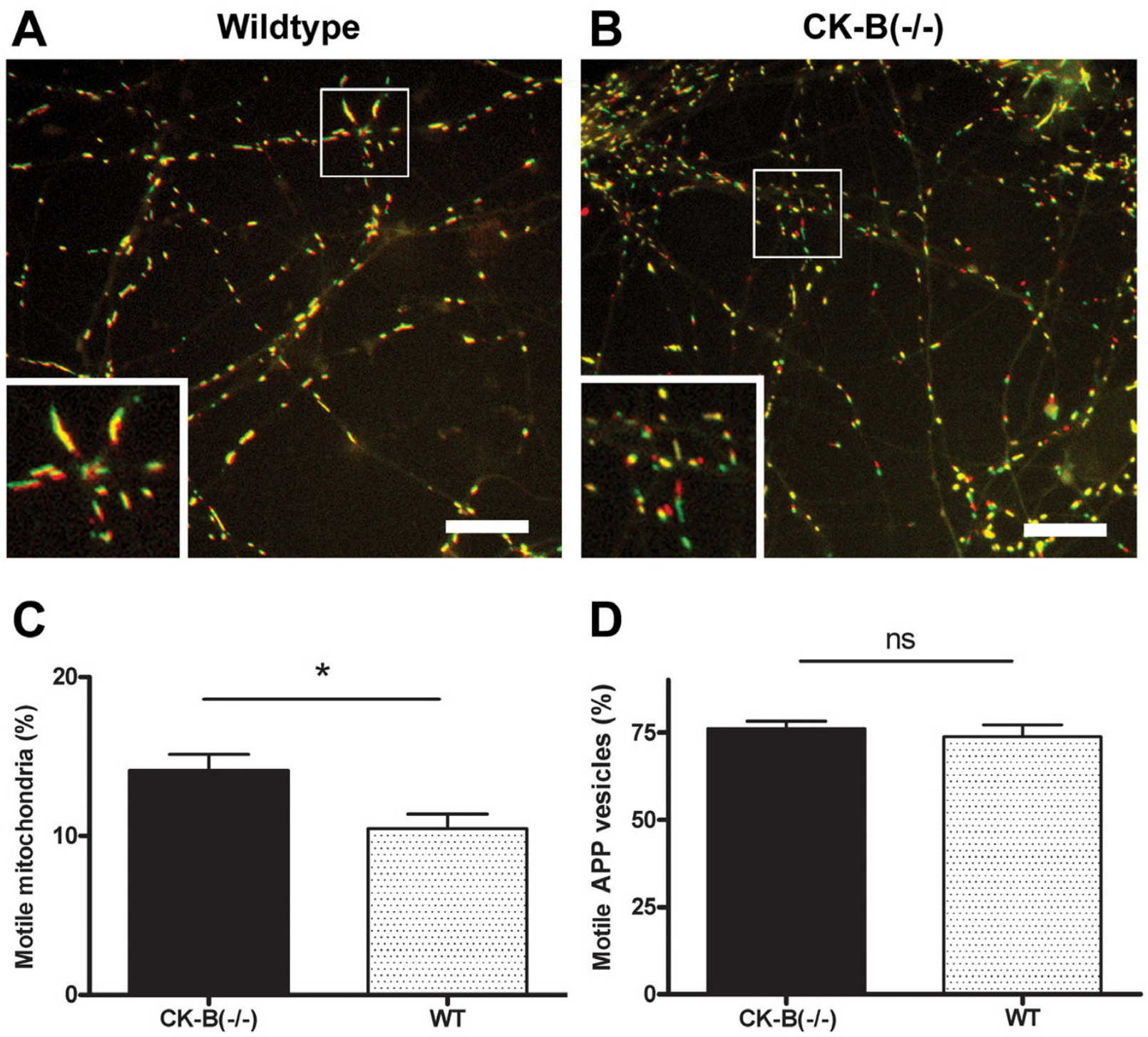

\section{Figure 4}

The percentage of motile mitochondria in wildtype and CK-B knockout neurons was determined. The first (red) frame and the $100^{\text {th }}$ frame (green) of a movie were merged. Yellow mitochondria are non-motile mitochondria. Panel A) |st and I00th frames of a movie of mitochondria in a wildtype neuron after merging. Panel B) displays the CK-B knockout equivalent. For wildtype $(n=12)$ and CK-B knockout $(n=15)$ movies were analyzed using the stack difference method (see methods). The percentage of motile mitochondria is presented in the scatter dot plot in panel $\mathbf{C}(\mathrm{p}<0.05)$. The percentage of motile YFP-APP particles in wildtype and CK-B knockout neurons was determined by analyzing 2 sets of merged frames from every movie (see also Additional Files I and 2). Panel D shows the average percentages (WT: 74\%; CK-B: 76\%; $P=0.57$ ) of motile YFP-APP vesicles (error bars represent SEM). $n=22$ for WT and $n=14$ for CK-B(-/-).

In conclusion, CK-B is not influencing the speed of intracellular transport of APP or mitochondria once this transport is initiated, however, in cells that lack CK-B a larger fraction of mitochondria is recruited into the actual motile pool.

\section{Discussion}

ATP generation and distribution is essential for the highly compartmentalized eukaryotic cell. Especially in neurons with their extended axonal and dendritic networks, it is important to modulate fuelling logistics. Spatially confined cellular processes like synapse functioning require local supply of energy. In order to fuel these functions 
optimally, they are coupled to sites of energy production. The CK system provides cells with a temporal and spatial ATP buffer to connect local energy consumption with sites of energy production $[16,28,37]$. Other phosphotransfer enzymes, like adenylate kinases and nucleoside diphosphate kinases are also active in neurons, and serve in the global network that distributes ATP throughout the cell. In addition, neurons have the capacity to relocate their energy production machinery to specialized subcellular sites to help in local ATP generation. Partitioning of glycolytic enzymes on cortical actin or membrane-near sites can provide local energy to membrane pumps by functional coupling $[38,39]$, whereas oxidative generated ATP can be generated locally, by recruiting mitochondria to sites of high ATP consumption such as synapses and dendritic spines $[9,35,40]$.

We focused on the question whether CK-B facilitates efficient axonal transport by comparing transport of APP and mitochondria in primary murine neurons derived from CK-B deficient and proficient mice.

Active transport of cargo in neurons is achieved by a wide variety of motor proteins, which are guided by the infrastructure of the cellular cytoskeleton [14]. These cargos can travel along actin filaments or microtubules either by plus end or minus end directed trafficing, thus facilitating both anterograde and retrograde axonal transport. Both types of cytoskeletal structures have their own assortment of motor proteins, which can be divided in actin-guided myosins [41] and microtubule-guided kinesins and dyneins [3]. A common denominator for myosins, dyneins and kinesins is that they require ATP hydrolysis to exert their function.

Fast axonal transport of membranous organelles and membrane proteins depends on highly processive motor activity and, consequently, a steady and adequate ATP/ ADP ratio for optimal fuelling of motor proteins. Our data show that the actual speed of fast axonal transport of APPYFP is not affected by CK-B deficiency. Although the maximum and average velocities observed are lower than reported for rat neurons [32], this may be a mouse related feature and no differences between wildtype cells and CK$\mathrm{B}$ deficient cells were found. In addition, mitochondrial transport velocities were not affected in CK-B knockout cells. Mitochondria are subject to saltatory movement, which involves cycles of anterograde and retrograde transport driven by kinesins and dyneins, respectively [40]. Because axons and dendrites in 7-day-old cultures of primary neurons are totally intertwined, we were unable to distinguish between axonal/dendritic or anterograde/retrograde transport. Therefore, and also because other groups have reported that mitochondrial velocity and the rate of anterograde and retrograde transport are highly similar in axons and dendrites of hippocampal neurons $[42,43]$, we decided not to discriminate between CK-B effects further. At this point, we thus consider it unlikely but can also not fully exclude - that CK-B deficiency affects the ratio of anterograde/retrograde transport of mitochondria.

We hypothesized that CK-B deficiency would bring about an altered capacity to distribute intracellular ATP, and create abnormal inhomogeneity in local ATP. Because neurons rearrange their mitochondria according to local ATP needs $[9,40]$, altered local ATP distribution may determine altered mitochondrial motility. The fact that no differences in either mitochondrial or YFP-APP velocities in combined anterograde/retrograde transport were found is therefore an interesting finding in its own right. Possibly, flexibility in the energetic network, with higher $\sim P$ flux through adenylate kinase (AK) or glycolytic enzymes helps to compensate the loss of CK-B [44-46], or - alternatively - mitochondria produce are still able to produce enough ATP to sustain their own transport.

Indeed, our findings suggest that initiation or abrogation of transport may be steps in the process that are more crucially dependent on cell energy state. Quantification of the fraction of mobile mitochondria revealed that CK-B deficient neurons contain on average 36\% more mitochondria in the motile fraction. The metabolic factors that modulate and mobilize mitochondrial motility are largely unknown. Local ATP depletion, or locally elevated $\mathrm{H}^{+}$and ADP levels caused by CK absence, could serve as a direct or indirect signal to attract mitochondria, or arrest nearby motor activity, arresting mitochondria while passing the "fuel-arid" area [40,47-49]. A combination of mechanistic events is also possible. In addition, secondary effects like inadequate $\mathrm{Ca}^{2+}$ handling, due to CK-B deficiency $[20,50]$, could act in signalling pathways for mitochondrial motility and/or docking [51]. For neurons, it has been found that local neuronal growth factor (NGF) application triggers mitochondrial recruitment through PI3K. Moreover, an intact F-actin cytoskeleton is required [52,53], which is organized by the action of formins and RhoA [54]. Interestingly, we recently found that CK-B increases the F-actin content in phagosomes [55]. Although the underlying molecular mechanisms of this effect on F-actin are yet unclear, it is tempting to speculate that CK-B deficiency in neurons could induce less efficient actin accumulation at sites of mitochondrial arrest. Indeed, a prominent role for actin-state in mitochondrial movement has been proposed [56]. Future research might help to discriminate between these different putative mechanisms.

\section{Conclusion}

We conclude that different types of axonal and dendritic transport in neurons do not directly require ATP gener- 
ated by CK-B. However, CK-B mediated phosphotransfer is functionally interconnected to events that determine the transport-initiation or -docking efficiency of mitochondria in neurons.

\section{Methods \\ Isolation and culture of primary neurons}

The generation of CK-B knockout mice and the study of genotype-phenotype relationships of these animals in comparison to wildtype controls has been described in detail elsewhere (also $[17,57])$. Primary cultures of mouse hippocampal neurons were established using a modified protocol [58]. In short, brains were isolated from CK-B(-/ -) [17] fetuses (E16.5) or fetuses of mixed background $(\mathrm{C} 57 \mathrm{BL} / 6 \times 129 \mathrm{Ola})$. Meninges were removed and hippocampi were separated from the hemispheres. Hippocampi were incubated for 20 minutes at $37^{\circ} \mathrm{C}$ in Hanks' Balanced Saline Solution (HBSS, Gibco) containing 0.05\% trypsin, $1 \mathrm{mM}$ EDTA and 20 mM HEPES (pH 7.35) and subsequently dissociated by pipetting and seeded onto $24 \mathrm{~mm}$ coverslips. Cells were allowed to attach for 3-4 hours in Neurobasal medium (Gibco), after which they were placed inverted on a layer of primary astrocytes (also see [58]). The co-culture was maintained in Neurobasal medium containing $1 \times$ B27 supplement (Gibco), $0.5 \mathrm{mM}$ glutamine and $0.05 \mathrm{mg} / \mathrm{ml}$ gentamycin (= $\mathrm{NBM}+$ ).

\section{Creatine kinase activity (zymogram)}

Cultured primary neurons ( 5 days in vitro) were lysed in buffer containing $12.6 \mathrm{mM} \mathrm{Na}_{2} \mathrm{HPO}_{4}, 2.8 \mathrm{mM} \mathrm{KH}_{2} \mathrm{PO}_{4^{\prime}}$ $0.05 \%$ Triton-x-100 and $0.3 \mathrm{mM}$ DTT. Zymogram analysis was performed as described [20] and, zymograms were subsequently developed using the colorimetric detection kit from Sigma Diagnostics (procedure number 715-EP).

\section{Indirect immunofluorescence}

Neurons (3-7 days in vitro) grown on glass coverslips were fixed with $2 \%$ paraformaldehyde in PHEM buffer $(25 \mathrm{mM}$ HEPES, $10 \mathrm{mM}$ EGTA, $60 \mathrm{mM}$ PIPES, $2 \mathrm{mM} \mathrm{MgCl}_{2}$, $\mathrm{pH}$ 6.9), permeabilized with $0.1 \%$ Triton $\mathrm{X}-100$ and incubated $20 \mathrm{~min}$ in PBS containing 4\% bovine serum albumine (BSA). CK-B was detected by subsequent incubation of monoclonal 21E10 (1:2000) [30] and goat-anti-mouse IgG conjugated to Alexa Fluor 488 (Molecular Probes). Images were taken with a Biorad MRC1024 confocal microscope using an oil immersion $60 \times$ objective.

\section{Transfection and rhodamine I 23 labeling of neurons}

Neurons (7 days in vitro) grown in glass bottomed $35 \mathrm{~mm}$ Willco dishes (GWSt-3522) were transfected using Nupherin-neuron (Biomol) transfection reagent in combination with Lipofectamine (Invitrogen). Per dish $0.5 \mu \mathrm{g}$ pcDNA3-APP-YFP (kind gift from Carlos Dotti [32]) and $2.5 \mu$ l Nupherin were premixed in phenol red free Neuro- basal medium and incubated for 10 minutes. An equal volume of phenol red free NBM with $1 \mu$ l Lipofectamine was added and after 30 minutes this mix was added to the neurons. After 2 hours the medium was replaced by $\mathrm{NBM}+$ medium and neurons were cultured for 24 hours prior imaging. For tracking mitochondria cells were loaded with rhodamine $123(10 \mu \mathrm{M})$ for 1 minute in $\mathrm{NBM}+\mathrm{w} / \mathrm{o}$ phenol red.

\section{Live imaging and image analysis}

Cells cultured on Willco dishes were imaged on an inverted microscope (Axiovert 200 M; Zeiss, Jena, Germany) equipped with a temperature controlled $\mathrm{CO}_{2}$ incubator (type S) and sample stage, and using a PlanApochromatic $63 \times 1.4$ oil immersion Plan NeoFluar DIC lens (Carl Zeiss GmbH, Jena, Germany). Rhodamine 123 was excited using a monochromator (Polychrome IV; TILL Photonics, Gräfelfing, Germany) set at $488 \mathrm{~nm}$. Images were recorded with the appropriate filter set (Omega Optical, Brattleboro, VT, USA) on a CoolSNAP HQ monochrome charge-coupled device (CCD) camera (Roper Scientific, Vianen, The Netherlands). All hardware was controlled with Metafluor 6 software (Molecular Devices Corp., Downingtown, PA, USA).

For particle (i.e. APP-cargo vesicles or mitochondria) tracing, sequential images were taken every 2 seconds to obtain image stacks of 100 images each. Particles were tracked using Metamorph 6 software (Molecular Devices Corp., Downingtown, PA, USA) software by marking them manually in subsequent frames (only particles that moved at least in 3 subsequent frames were tracked). The velocity per particle-vesicle was calculated by dividing the travelled distance by time. Additionally, for each moving particle the maximal velocity (during two subsequent frames) was determined. The number of analysed particles is mentioned in the text or legends.

To estimate the percentage moving mitochondria the same dataset as mentioned above was analyzed with Image software version 1.34s (U. S. National Institutes of Health, Bethesda, Maryland, USA, http://rsb.info.nih.gov/ ii/). The original image stacks were converted to binary stacks by manually applying a threshold, according to the quality of each individual stack. The total number of mitochondria in the stack was counted using the particle count function ( $5<$ mitochondria $<50$ pixels). To distinguish between moving and stationary mitochondria, every frame " $n$ " was compared to an earlier frame "n-3" ("stackdifference" option from the ImageJ kymograph plugin, EMBL, Heidelberg, Germany). The resulting stack of images contains motile mitochondria, which were counted. Numbers obtained were divided by two to compensate for double counting of both "old and new" mitochondrial positions in "difference-stack" images. Finally, 
percentages of motile mitochondria in the stacks were calculated. For more information see Additional file 1.

\section{Authors' contributions}

BW was responsible for project planning. JWPK, JAMF and BW conceived and designed the experiments. JWPK performed most of the experiments. JAMF contributed to microscopic analyses. FTJJO contributed methodology and performed experiments. JWPK and BW wrote the paper. All authors read and corrected the paper and added suggestions.

\section{Acknowledgements}

This work was supported by NWO ZON-MW Program grant 901-01-191 and partly by grants KUN 2002-1763 and KUN 2004-3I25 from the Dutch Cancer Society (Nederlandse Kankerbestrijding NKB/KWF to B.W.).

\section{References}

I. Brown A: Axonal transport of membranous and nonmembranous cargoes: a unified perspective. J Cell Biol 2003, 160:817-82I.

2. Chen H, Chan DC: Critical dependence of neurons on mitochondrial dynamics. Curr Opin Cell Biol 2006, 18:453-459.

3. Goldstein LS, Yang Z: Microtubule-based transport systems in neurons: the roles of kinesins and dyneins. Annu Rev Neurosci 2000, 23:39-7I.

4. Lipton P, Robacker K: Glycolysis and brain function: $[K+] \mathbf{o}$ stimulation of protein synthesis and $\mathrm{K}+$ uptake require glycolysis. Fed Proc 1983, 42:2875-2880.

5. Lim L, Hall C, Leung T, Mahadevan L, Whatley S: Neurone-specific enolase and creatine phosphokinase are protein components of rat brain synaptic plasma membranes. J Neurochem | 983, 41: | |77-| | 82.

6. Bernstein BW, Bamburg JR: Actin-ATP hydrolysis is a major energy drain for neurons. J Neurosci 2003, 23:1-6.

7. Ames A 3rd: CNS energy metabolism as related to function. Brain Res Brain Res Rev 2000, 34:42-68.

8. Pellerin L, Magistretti PJ: Neuroenergetics: calling upon astrocytes to satisfy hungry neurons. Neuroscientist 2004, 10:53-62.

9. Verstreken P, Ly CV, Venken KJ, Koh TW, Zhou Y, Bellen HJ: Synaptic mitochondria are critical for mobilization of reserve pool vesicles at Drosophila neuromuscular junctions. Neuron 2005, 47:365-378.

10. Nangaku M, Sato-Yoshitake R, Okada Y, Noda Y, Takemura R, Yamazaki $\mathrm{H}$, Hirokawa N: KIFIB, a novel microtubule plus enddirected monomeric motor protein for transport of mitochondria. Cell 1994, 79:1209-1220.

II. Tanaka Y, Kanai Y, Okada Y, Nonaka S, Takeda S, Harada A, Hirokawa N: Targeted disruption of mouse conventional kinesin heavy chain, kif5B, results in abnormal perinuclear clustering of mitochondria. Cell 1998, 93: | I47-1 I58.

12. Morris RL, Hollenbeck PJ: Axonal transport of mitochondria along microtubules and $F$-actin in living vertebrate neurons. J Cell Biol 1995, 131:1315-1326.

13. Sturmer K, Baumann O, Walz B: Actin-dependent light-induced translocation of mitochondria and ER cisternae in the photoreceptor cells of the locust Schistocerca gregaria. J Cell Sci 1995, 108 ( Pt 6):2273-2283.

14. Vale RD: The molecular motor toolbox for intracellular transport. Cell 2003, I I 2:467-480.

15. Dzeja PP, Terzic A: Phosphotransfer networks and cellular energetics. J Exp Biol 2003, 206:2039-2047.

16. Wallimann T, Hemmer W: Creatine kinase in non-muscle tissues and cells. Mol Cell Biochem 1994, I33-134:193-220.

17. Jost CR, Van Der Zee CE, In 't Zandt HJ, Oerlemans F, Verheij M, Streijger F, Fransen J, Heerschap A, Cools AR, Wieringa B: Creatine kinase $B$-driven energy transfer in the brain is important for habituation and spatial learning behaviour, mossy fibre field size and determination of seizure susceptibility. Eur J Neurosci 2002, 15:1692-1706.
18. van Deursen J, Heerschap A, Oerlemans F, Ruitenbeek W, Jap P, ter Laak $\mathrm{H}$, Wieringa $B$ : Skeletal muscles of mice deficient in muscle creatine kinase lack burst activity. Cell 1993, 74:62I-63I.

19. Tachikawa M, Fukaya M, Terasaki T, Ohtsuki S, Watanabe M: Distinct cellular expressions of creatine synthetic enzyme GAMT and creatine kinases UCK-Mi and CK-B suggest a novel neuron-glial relationship for brain energy homeostasis. Eur J Neurosci 2004, 20: I44-160.

20. Steeghs K, Benders A, Oerlemans F, de Haan A, Heerschap A, Ruitenbeek W, Jost C, van Deursen J, Perryman B, Pette D, Bruckwilder M, Koudijs J, Jap P, Veerkamp J, Wieringa B: Altered Ca2+ responses in muscles with combined mitochondrial and cytosolic creatine kinase deficiencies. Cell 1997, 89:93-103.

21. Dzeja PP, Bortolon R, Perez-Terzic C, Holmuhamedov EL, Terzic A: Energetic communication between mitochondria and nucleus directed by catalyzed phosphotransfer. Proc Natl Acad Sci U S A 2002, 99:10156-10161.

22. Saks VA, Khuchua ZA, Vasilyeva EV, Belikova OY, Kuznetsov AV: Metabolic compartmentation and substrate channelling in muscle cells. Role of coupled creatine kinases in in vivo regulation of cellular respiration--a synthesis. Mol Cell Biochem 1994, 133-134:155-192.

23. Guillaud L, Setou M, Hirokawa N: KIFI 7 dynamics and regulation of NR2B trafficking in hippocampal neurons. J Neurosci 2003, 23:| $31-140$

24. Wong RW, Setou M, Teng J, Takei Y, Hirokawa N: Overexpression of motor protein KIFI7 enhances spatial and working memory in transgenic mice. Proc Natl Acad Sci U S A 2002, 99: 14500-14505.

25. Yuen EY, Jiang Q, Feng J, Yan Z: Microtubule regulation of $\mathbf{N}$ methyl-D-aspartate receptor channels in neurons. J Biol Chem 2005, 280:29420-29427.

26. Shah JV, Cleveland DW: Slow axonal transport: fast motors in the slow lane. Curr Opin Cell Biol 2002, 14:58-62.

27. Brady ST, Lasek RJ: Nerve-specific enolase and creatine phosphokinase in axonal transport: soluble proteins and the axoplasmic matrix. Cell I98I, 23:5।5-523.

28. Friedman DL, Roberts R: Compartmentation of brain-type creatine kinase and ubiquitous mitochondrial creatine kinase in neurons: evidence for a creatine phosphate energy shuttle in adult rat brain. J Comp Neurol 1994, 343:500-5I I.

29. Hemmer W, Zanolla E, Furter-Graves EM, Eppenberger HM, Wallimann T: Creatine kinase isoenzymes in chicken cerebellum: specific localization of brain-type creatine kinase in Bergmann glial cells and muscle-type creatine kinase in Purkinje neurons. Eur J Neurosci 1994, 6:538-549.

30. Sistermans EA, de Kok YJ, Peters W, Ginsel LA, Jap PH, Wieringa B: Tissue- and cell-specific distribution of creatine kinase $B$ : a new and highly specific monoclonal antibody for use in immunohistochemistry. Cell Tissue Res 1995, 280:435-446.

31. Koo EH, Sisodia SS, Archer DR, Martin LJ, Weidemann A, Beyreuther K, Fischer P, Masters CL, Price DL: Precursor of amyloid protein in Alzheimer disease undergoes fast anterograde axonal transport. Proc Natl Acad Sci U S A 1990, 87:156I- 1565.

32. Kaether C, Skehel P, Dotti CG: Axonal membrane proteins are transported in distinct carriers: a two-color video microscopy study in cultured hippocampal neurons. Mol Biol Cell 2000, I I: I213-1224.

33. Kamal A, Stokin GB, Yang Z, Xia CH, Goldstein LS: Axonal transport of amyloid precursor protein is mediated by direct binding to the kinesin light chain subunit of kinesin-I. Neuron 2000 , 28:449-459.

34. Chan DC: Mitochondria: dynamic organelles in disease, aging, and development. Cell 2006, I25: 124|-1252

35. Li Z, Okamoto K, Hayashi Y, Sheng M: The importance of dendritic mitochondria in the morphogenesis and plasticity of spines and synapses. Cell 2004, I 19:873-887.

36. Morris RL, Hollenbeck PJ: The regulation of bidirectional mitochondrial transport is coordinated with axonal outgrowth. Cell Sci 1993, 104 ( Pt 3):917-927.

37. Tombes RM, Shapiro BM: Metabolite channeling: a phosphorylcreatine shuttle to mediate high energy phosphate transport between sperm mitochondrion and tail. Cell 1985, 41:325-334.

38. Xu KY, Zweier JL, Becker LC: Functional coupling between glycolysis and sarcoplasmic reticulum $\mathrm{Ca}+$ transport. Circ Res 1995, 77:88-97. 
39. Glitsch HG, Tappe A: The $\mathbf{N a + / K + ~ p u m p ~ o f ~ c a r d i a c ~ P u r k i n j e ~}$ cells is preferentially fuelled by glycolytic ATP production. Pflugers Arch 1993, 422:380-385.

40. Hollenbeck PJ, Saxton WM: The axonal transport of mitochondria. J Cell Sci 2005, I I 8:54 I I-54I9.

4I. Sellers JR: Myosins: a diverse superfamily. Biochim Biophys Acta 2000, I 496:3-22.

42. Ligon LA, Steward O: Movement of mitochondria in the axons and dendrites of cultured hippocampal neurons. J Comp Neurol 2000, 427:340-350.

43. Overly CC, Rieff HI, Hollenbeck PJ: Organelle motility and metabolism in axons vs dendrites of cultured hippocampal neurons. J Cell Sci 1996, 109 ( Pt 5):97I-980.

44. Janssen E, de Groof A, Wijers M, Fransen J, Dzeja PP, Terzic A, Wieringa B: Adenylate kinase I deficiency induces molecular and structural adaptations to support muscle energy metabolism. J Biol Chem 2003, 278: I 2937-I 2945.

45. de Groof AJ, Smeets B, Groot Koerkamp MJ, Mul AN, Janssen EE, Tabak HF, Wieringa B: Changes in mRNA expression profile underlie phenotypic adaptations in creatine kinase-deficient muscles. FEBS Lett 200I, 506:73-78.

46. de Groof AJ, Oerlemans FT, Jost CR, Wieringa B: Changes in glycolytic network and mitochondrial design in creatine kinasedeficient muscles. Muscle Nerve 200 I, 24: I I88-I I 96.

47. Mironov SL: ADP regulates movements of mitochondria in neurons. Biophys J 2007, 92:2944-2952.

48. Hollenbeck PJ: The pattern and mechanism of mitochondrial transport in axons. Front Biosci 1996, I:d91-102.

49. Terada S, Kinjo M, Hirokawa N: Oligomeric tubulin in large transporting complex is transported via kinesin in squid giant axons. Cell 2000, I 03: $|4|-\mid 55$.

50. de Groof AJ, Fransen JA, Errington RJ, Willems PH, Wieringa B, Koopman WJ: The creatine kinase system is essential for opti$\mathrm{mal}$ refill of the sarcoplasmic reticulum $\mathrm{Ca2}+$ store in skeletal muscle. J Biol Chem 2002, 277:5275-5284.

5I. Yi M, Weaver D, Hajnoczky G: Control of mitochondrial motility and distribution by the calcium signal: a homeostatic circuit. J Cell Biol 2004, 167:66I-672.

52. Chada SR, Hollenbeck PJ: Nerve growth factor signaling regulates motility and docking of axonal mitochondria. Curr Biol 2004, I 4: I 272-I276.

53. Chada SR, Hollenbeck PJ: Mitochondrial movement and positioning in axons: the role of growth factor signaling. J Exp Biol 2003, 206:1985-1992.

54. Minin AA, Kulik AV, Gyoeva FK, Li Y, Goshima G, Gelfand VI: Regulation of mitochondria distribution by RhoA and formins. J Cell Sci 2006, I I 9:659-670.

55. Kuiper JW, Pluk $H$, Oerlemans $F$, van Leeuwen FN, de Lange $F$, Fransen J, Wieringa B: Creatine kinase-mediated ATP supply fuels actin-based events in phagocytosis. PLoS Biol 2008, 6:e5I.

56. Boldogh IR, Pon LA: Mitochondria on the move. Trends Cell Biol 2007, I 7:502-5 I0.

57. Streijger F, In 't Zandt HJ, Renema WK, Oerlemans F, Heerschap A, Kuiper JW, Pluk H, Jost C, Van Der Zee CE, Wieringa B: Developmental and functional consequences of disturbed energetic communication in brain of creatine kinase-deficient mice: Understanding CK's role in the fuelling of behavior and learning. In Molecular system bioenergetics Edited by: Saks VA. Weinheim, Wiley-VCH Verlag GmbH \& Co. KGaA; 2007:339-366.

58. Hoop de MJ, Meyn L, Dotti CG: Culturing hippocampal neurons and astrocytes from fetal rodent brain. In Cell Biology: a laboratory handbook Volume I. 2nd edition. Edited by: Celis JE. San Diego, Academic Press; 1998: I54-163.

\section{Competing interests}

The authors of this manuscript declare that they have no competing interests.

\section{Publish with Biomed Central and every} scientist can read your work free of charge

"BioMed Central will be the most significant development for disseminating the results of biomedical research in our lifetime. "

Sir Paul Nurse, Cancer Research UK

Your research papers will be:

- available free of charge to the entire biomedical community

- peer reviewed and published immediately upon acceptance

- cited in PubMed and archived on PubMed Central

- yours - you keep the copyright
BioMedcentral 